\title{
CRUZANDO IMAGENS EM \\ CONTEXTOS RURAIS
}

Vanda Aparecida da Silva**

Resumo: Neste texto pretendo dar conta de expor, primeiramente, como surgiu a motivação para o uso da imagem nas pesquisas realizadas em dois contextos rurais, numa Aldeia do Baixo Alentejo, Portugal, e num município da região do Vale do Jequitinhonha (MG), no Brasil. Na sequência, a maneira como fui integrando os vários elementos e propostas teóricas, no âmbito de projetos acerca das experiências e representações da sexualidade, junto a populações que se encontram na dinâmica de ir e vir, entre espaços rurais e urbanos. E, por fim, demonstrar como a utilização dos recursos audiovisuais num trabalho etnográfico resultou na aproximação e interface com a antropologia visual e com a história oral; bem como, numa fonte de conhecimento e aprendizagem.

Palavras-chave: Imagem. Metodologia. Sexualidade. Rural.

Abstract: In this paper I intend to expose, first, how did the motivation to use the image in the research conducted in two rural contexts, a village in Alentejo, Portugal and a county in the Vale do Jequitinhonha (MG), Brazil. Further, the way I was integrating the various elements and theoretical positions within projects on the experiences and representations of sexuality, along with populations that are in the dynamics of movement, between rural and urban 
spaces. And finally, to demonstrate how the use of audiovisual resources resulted in an ethnographic approach and interface with visual anthropology and oral history, as well as a source of knowledge and learning. 
Nos trabalhos realizados tanto no Brasil quanto em Portugal, a imagem foi pensada enquanto um mobilizador da consciência que pode desencadear o reverberar de sentimentos e situações históricas (SONTAG, 1981; FONSECA, 1995); um objeto de conhecimento que pode traduzir os modos como os sujeitos fotografados/ filmados lidam com a imagem, o significado que esta tem para a população estudada, e o que é dado (ou não) a conhecer e captar (MARTINS, 2008). Assim, e embora seja no trabalho realizado no Brasil que a experiência com a utilização dos recursos audiovisuais dá o tom analítico à utilização destes, neste texto, a exposição será feita sob inspiração da investigação realizada em contexto português. Sobretudo porque se trata de um trabalho mais recente e novos ângulos puderam ser explorados a partir desta pesquisa. Deste modo, tal pesquisa junto a população jovem e adulta de uma Aldeia do Baixo Alentejo ${ }^{1}$ se situa num cenário da vida moderna e das transformações por que vem passando Portugal, sobretudo depois do 25 de abril de $1974^{2}$ e de sua entrada na União Europeia, nos idos de 1986.

Os moradores desta Aldeia do Baixo Alentejo vivem dos cultivos de olival, culturas industriais (por exemplo, o azeite), pastagens permanentes; da pecuária que é expressiva na criação de ovinos, aves e suínos. Além dos trabalhos nos pequenos comércios, de roupas, alimentos, remédios; atendimentos nos cafés e restaurantes; serviços administrativos na Junta de Freguesia, na agência bancária e outras repartições públicas, como o Centro de Saúde, e a escola primária. Visto que a mobilidade parece ter se tornado numa exigência contemporânea (SANTOS, 2002), a Aldeia do Baixo Alentejo apresenta-se com expressiva movimentação. Esta movimentação pode ser vislumbrada especialmente junto a popu- 
lação jovem e adulta, que combinam idas e vindas deslocando-se para trabalho e ou estudo, em território nacional ou internacional. Alguns integram as migrações temporárias indo trabalhar nas colheitas de maçã e pêssego, na Espanha e/ou na França; nos serviços de hotelaria, na Suíça, por exemplo. Além disso, buscam diversão, consumo e serviços, como os de saúde, nas aldeias, vilas vizinhas e em outras cidades. Mas a realidade aldeã também corrobora o estado do mundo rural português: o de crescente envelhecimento populacional.

Daí que uso do vídeo procurou explorar as diferentes mobilidades dos moradores, com especial enfoque nos jovens. Estes, através da sociabilidade, exercitam-se e experimentam as múltiplas maneiras disponíveis de comunicação; vivendo uma espécie de "intercâmbio efetivo" (SANTOS, 2002, p. 319) entre os mundos da Aldeia e da cidade, do espaço nacional e do espaço estrangeiro. Neste sentido, tal recurso para a elaboração de um texto em imagens integrou-se ao tema da sexualidade, posto que é pensado enquanto sentimento amoroso/afetivo. Tornando possível explorar, portanto, dimensões da afetividade, contemplando a dimensão amorosa e "todas as outras formas de afetividade: a maternal, a paternal, a parental, a erótica e sexual, a amizade, o companheirismo" (TORRES, 2004, p. 36), com a utilização do vídeo e da fotografia.

A utilização do recurso audiovisual não teria tanto relevo e fácil aceitação na pesquisa sobre experiências e representações da sexualidade se os sujeitos sociais também não estivessem incorporando, no cotidiano, os elementos e mecanismos de informação e comunicação disponíveis. Por sua vez, enriquecendo o espaço aldeão dando-lhe novas dimensões. 


\section{Os recursos audiovisuais}

O uso da fotografia e do vídeo na pesquisa no Baixo Alentejo visava inicialmente a formação de um banco de dados (um diário de campo imagético), de tal maneira que pudesse reavivar a memória da pesquisadora, sobretudo nos períodos em que me encontrava distante dos sujeitos sociais; sobretudo porque optou-se por não morar na Aldeia. ${ }^{3}$ Todavia, e sem que inicialmente tivesse me dado conta, minha movimentação em relação à Aldeia acabou sendo guiada pelo ritmo dos seus moradores, principalmente através daqueles com quem fui estabelecendo maior intimidade e amizade. Portanto, quando achei que estava fazendo uma opção fui me apercebendo que fazia a dinâmica de muitos dos jovens aldeões que viviam fora e retornavam nos finais de semana, momentos de festividades e acontecimentos comemorativos. Por conseguinte, também tornei-me numa espécie de "acontecimento" quando de minha visita (GEERTZ, 1989). Tal interação foi tecida por meio de visitas sucessivas. No começo, alugando um quarto (na casa de uma família), permanecendo, em média, uma semana; noutros momentos, sendo uma visita (amiga) que vai para passar o final de semana (coisa que se transformava em mais anotações de terreno). Até chegarmos ao ponto do contrário também ocorrer, e a pesquisadora servir de hospedeira para a mãe e filha, entrevistadas e amigas (por precisarem comparecer às consultas médicas em Lisboa). As minhas visitas e contatos com moradores da A1deia, portanto, não obedeceram a uma periodicidade rígida, assim como, não aconteceram unicamente no lugar de morada desses. E na interação com as pessoas falou-se sobre todos os assuntos da vida cotidiana, assim como procurou-se participar de algumas das suas múltiplas deslocações pelos diferentes espaços. ${ }^{4}$ 
Assim, foi através de sucessivas visitas ao campo que a pesquisa $^{5}$ etnográfica (GEERTZ, 1989) e qualitativa, com base na observação participante, pode ser realizada. $\mathrm{O}$ primeiro ato fotográfico na Aldeia aconteceu num momento de festividade dos jovens, e talvez por isto pude fazer uso da máquina fotográfica logo na minha primeira visita. Depois, por meio de um convite para fazer parte da rede social "Hi-5", pude ter acesso às fotografias que disponibilizavam na rede. Entretanto, o uso da câmera de vídeo veio mais tarde, quando já me encontrava mais enturmada com os jovens e demais moradores da Aldeia. A partir disto foi possível ir considerando a possibilidade de avançar para a elaboração do texto visual, um vídeo.

Entretanto, tinha que considerar o que aprendi com experiência da pesquisa no Brasil: que nem toda representação que julgamos criar acerca dos sujeitos podem corresponder à sua autoimagem ou representação. Observação esta que nasceu da minha experiência inicial com a utilização da imagem em contexto rural, e da devolução deste resultado no âmbito do meu mestrado utilizando fotografias. ${ }^{7}$ Para além de alguns elogios que recebi quando da apresentação para um grupo de professores e diretora da escola local, a recusa da imagem, por parte de uma das expectadoras, foi o que motivou todo o meu esforço analítico acerca da utilização dos recursos de captação da imagem na pesquisa. $\mathrm{O}$ que me fez perceber que na captação, quase sempre, não estamos isentos da dimensão política, daquilo que está incorporado (em nós) antes de tornar-se flagrante por intermédio das fotografias. Ou seja, "componentes de ordem imaterial", tais como, "[...] filtros individuais: psicológicos, sociais, ideológicos etc.; e repertório pessoal: bagagem artística, habilidade técnica, experiências." (KOSSOY, 
2000, p. 32 apud SILVA, 2007). Esta segunda, muitas vezes, ainda negligenciada. Ou seja, parece que devido a necessidade de tempo de dedicação, de dinheiro contribui para que alguns pesquisadores acabem por investir pouco na aprendizagem e conhecimento da linguagem visual.

Todavia, o ato de fotografar parece não ser suficiente para tirar-nos de nós mesmos, de nossa "clausura", de tal modo que caímos na reprodução da forma unidimensional dos "tipos humanos" (GODOLPHIM, 1995, p. 128). Assim sendo, acabamos por determinar ou confirmar "tipos e papéis sociais" fortemente influenciados por “julgamentos 'pré-fabricados' (estigmatizados, rotulados)”, principalmente porque não damos "conta da tendência valorativa, política ou emocional com que se fotografa", ao mesmo tempo em que se está construindo representações.

$\mathrm{Na}$ Aldeia, passei a fazer uso da câmera filmadora ${ }^{8}$ ao mesmo tempo em que ia criando um universo de confrontos das imagens (em mim e nos sujeitos). O uso de tal equipamento, sem nenhum retoque, edição, corte ou outra interferência [que não o apertar do botão "rew" (rebobinar) da câmera para demonstrar a imagem captada, às pessoas]. E, talvez, por ser mais empolgante terem a ideia do filme (vídeo) que estava sendo feito, em mim também crescia alguma ideia de que poderia ter maior segurança acerca da edição final, provocando um mínimo de suscetibilidades. Por fim, a autoria está nas mãos do pesquisador ou de quem edita? Para Foucault, o autor desaparece no ato da criação, ele passa a ter uma "função autor" assumindo diferentes posições na circulação e funcionamento dos discursos (FOUCAULT, 2002). Neste caso, o trabalho de elaboração do roteiro esteve sob responsabilidade da pesquisadora, todavia, tal roteiro acabou por ser direcionado não 
somente pelos objetivos estabelecidos na pesquisa, mas pelos diálogos que se estabeleceu com uma profissional da edição. ${ }^{9}$ Deste encontro nasceu o vídeo etnográfico experimental intitulado "Para Ti Amor" (duração: 12 min.).

No caso de um vídeo etnográfico - apesar da edição e produção serem voltados para os objetivos da pesquisa - os sujeitos ver-se-ão não apenas na condição de emissores e receptores de si próprios, mas também perante a representação do(a) pesquisador(a) sobre eles. Então, a utilização desta técnica na pesquisa etnográfica traz um ganho à relação, pelo contato com os sujeitos filmados, seja no final da pesquisa, seja num ato mais imediato de poder mostrar o que foi gravado. Para o caso da Aldeia do Baixo Alentejo, fui confrontada com os sentimentos de expectativa acerca daquilo que iriam ver, mas também pela desconfiança; sobretudo se levar em consideração o fato de que quem captou as imagens foi uma pesquisadora estrangeira (e brasileira), numa zona fronteiriça entre Portugal e Espanha. Sentimento tal que talvez encontre na própria condição de moradores de Aldeia sua razão de existir, sinalizando, por sua vez, para a necessidade de também serem criadores de sua imagem. Não por acaso, no transcorrer das muitas visitas ao terreno, pude saber e acompanhar a criação de um site na internet com fotografias, fragmentos de vídeo, especialmente das festas anuais da Santa padroeira da Aldeia; um blog, de autoria de um morador local, com fotografias de plantas, pássaros, imagens da flora alentejana; gravação da entrevista de uma moradora a falar de sua trajetória pessoal enquanto empreendedora local.

Deste modo, observa-se o forte impacto que a internet tem junto aos jovens e demais moradores. Especialmente para os jovens que veem neste recurso um particular espaço para veiculação de 
suas imagens, de comunicação e de criação à margem dos mecanismos de vigilância ou controle legal das autoridades (CAMPOS, 2009; PAIS, 2005). Sendo assim, mais do tomar como dado ou como um banco de dados disponível e banalizado, vi que a internet, bem como, todas as outras formas de registro audiovisual que os jovens estavam utilizando, poderia ser um importante campo a ser desvendado na relação entre a pesquisadora e os seus sujeitos.

\section{Para além da ilustração}

Minha ambição com a utilização da fotografia e do vídeo enquanto técnica de captura de imagem e som foi e é para além da simples ilustração comprovativa de que "estive lá". Tal trabalho pode ser entendido como uma "escrita visual" que, por sua vez, está fortemente influenciada pela oralidade e a sua semelhança com as novas tecnologias, especialmente, a televisão. Uma vez que todo telespectador, mais cedo ou mais tarde, acaba por emitir algum comentário ou reflexão acerca daquilo que viu, este pode ser o eixo que aglutina e articula o conhecimento sobre o modo como as pessoas emitem opiniões, remotas ou autorreferentes.

Neste sentido é que observar o modo como interpretam aquilo que veem/ouvem (na mídia impressa ou televisiva) e como utilizam o vídeo, a fotografia, pode ser um importante suporte para o uso do vídeo como um método (PINK, 2001, p. 80), e também uma maneira de dialogar (e ou negociar) com os sujeitos. Neste instante, estamos diante da possibilidade de contribuir para identificar e reconhecer emoções, sentimentos e sensações no âmbito de um contexto em particular para melhor interpretá-lo. Este jogo 
não termina, posto que é uma "operação de distinção e de relacionamento", um processo em dupla via de "saber" e "conhecer" (PIAULT, 1995).

Deste modo, quando se busca as afinidades que possam existir entre as novas tecnologias e a oralidade, nota-se que o vídeo visto pelos sujeitos que foram filmados desperta os mais variados comentários na plateia. Por sua vez esta acaba por interferir, completar, reagir na tentativa de transformar a imagem que viu na tela. A ideia de que o vídeo possibilita a "participação" dos sujeitos filmados (ou outros, mas do mesmo contexto) traz em si elementos da "noética" oral (FONSECA, 1995); ou seja, esta "fala-reflexão" (ALMEIDA, 2001) dos sujeitos com aquela/aquele que produziu algo sobre eles. Noutra direção, a programação transmitida pela televisão tem a sua autonomia e, por isso, tal relação de interferir na imagem projetada não acontece. Porém, outras imagens podem ser criadas ou projetadas para fora do aparelho de televisão, nos espectadores, não menos nos jovens e adultos do contexto rural português ou brasileiro. Tais como sonhos ou projeções de maior liberdade para as experiências afetivo-amorosas e de consumo.

$\mathrm{Na}$ Aldeia alentejana, sobretudo entre jovens e adultos, vê-se um substancial uso dos instrumentos de difusão e captação de imagem: televisão, máquinas fotográficas (digitais, de telemóvel), câmera de vídeo e também a difusão da imagem via internet ( $s i$ tes/blog da Aldeia; chats, fotologs, comunidades de redes sociais Hi-5 e Facebook...). Não por acaso, logo no primeiro dia de minha visita ao terreno, durante a noite em que caminhava pelas ruas, minha primeira visão da Aldeia foi um pequeno aglomerado de jovens observando um rapaz que produzia um desenho (pintado a aerosol). O que vi se tratava de um "writer" ${ }^{10}$. Tempos depois 
soube que seria para a festa na discoteca local. Desenho que ficou registrado pelo clicar de minha câmera fotográfica. Outro exemplo: perguntas que (jovens ou adultos) me fizeram sobre uma determinada telenovela brasileira (exibida pela empresa portuguesa de televisão SIC, ou a Globo News - TV a cabo), querendo saber da veracidade de tal episódio ou comportamento; ou se as pessoas fazem assim ou assado, no Brasil... Ou mesmo quando convidaram a pesquisadora para participar da comunidade de amigos no $\mathrm{Hi}$-5, ou entrar no Skype. Assim, como é que o vídeo pode constituir-se numa narrativa/texto audiovisual, numa pesquisa acerca dos afetos e da sexualidade?

Considerando o cenário contemporâneo em torno das questões do sexo, prazer e múltiplas informações proferidas por diferentes meios de comunicação, a intenção com o vídeo etnográfico (exploratório) não foi partir daquilo que está "muito exposto", mas trazer alguns elementos que dizem da linguagem cotidiana, de jovens e adultos, em torno dos afetos e da sexualidade, localizando os espaços de homens e mulheres, na Aldeia do Baixo Alentejo. Minha preocupação foi problematizar, a partir dos dados etnográficos, principalmente de imagens que (obedecendo a pré-edição realizada através visualização e o feedback dos próprios sujeitos), sobretudo considerando as imagens censuradas e as que não foram ou puderam aparecer no vídeo editado. Nestes termos, a imagem capturada (e editada) serviu como um "paradigma indiciático"11. Algo com o poder de trazer à tona aquilo que estava interdito, mas que por meio da visualização pode desencadear outros discursos e reflexões acerca dos próprios sentimentos, da vida afetiva-sexual, mas também do lugar em que se vive. Deste modo, as fotografias, o vídeo, bem como outros meios de gravação e reprodução digitais, 
servem como "dispositivos memoriais" (SOBRAL, 2006, p. 31). A própria presença de alguém de fora com um gravador, câmeras pode ser um acontecimento detonador de outras imagens. Daí que o investimento no uso de aparatos tecnológicos aumenta ainda mais o nosso compromisso e responsabilidade com aquilo que criamos acerca dos nossos objetos de estudo (HARAWAY, 1995).

\section{Outras imagens}

A presença do(a) pesquisador(a) pode desencadear questionamentos, projeções e temores. Um destes pode advir do falar acerca da realização de uma pesquisa que envolva os jovens e descortinar o que está subjacente: a ideia de que estes são problema, envolvem-se em situações conflituosas e ou tensas. Um exemplo vivido ocorreu num convívio com alguns rapazes da Aldeia alentejana. Destaco o trecho de um depoimento que pode ser significativo e sinalizar para pensar o modo como alguns jovens veem-se, enquanto grupo social e quiçá pensem sobre a própria condição de viver na Aldeia. Comentou o rapaz: "Você veio aqui para ver que nós não fazemos mal a ninguém... [pausa] A gente só faz mal à gente mesmo..." (15 anos, não estudante, membro da Associação Juvenil, trabalha com o pai como ajudante). Ou seja, tal comentário talvez traduza a reflexão-imagem que alguns jovens têm sobre eles próprios, qual seja, de que eles não são ou não querem ser vistos como um "problema" para a família, ou para a sociedade; e dizer do papel que alguns jovens julgam ter dentro da Aldeia, como no caso citado, uma vez que este faz parte da Associação Juvenil ${ }^{12}$, que é o de promover eventos, colaborar nas atividades 
sociais, dinamizar a vida cotidiana enquanto "organizam atividades essencialmente dirigidas a jovens residentes nesta região um pouco envelhecida", como nas palavras de um ex-presidente da Associação (25 anos, casado, não estudante, trabalha no comércio local) (SILVA, 2011). Ao exibir o vídeo experimental, a reação, sobretudo dos jovens, diante da visualização também soma à ideia/ sentimento de pertencimento, pois logo dizem: "Isto é mesmo a Aldeia!”.

Se os jovens e demais moradores da Aldeia alentejana, de um modo direto ou indireto, utilizam as inovações tecnológicas com especial intensidade, observa-se que tal uso visa, sobretudo, o registro e o fomento das redes de amizades, sociabilidades. Mas, nos dias que seguem, sobretudo entre adultos e jovens com maior familiaridade com os usos (e abusos) da utilização da imagem, não fui poupada das indagações ou insinuações: "veja lá o que vais passar lá no Brasil!” (homem, aproximadamente 50 anos), enquanto filmava-o lavando "caracoletas"13 que apanhara no campo; "então, isto é para quê...? Vais vender?" (rapaz, de aproximadamente 25 anos), comentário feito enquanto filmava mãe e filhos que são pasteleiros na Aldeia.

Ao que tudo indica, ao mesmo tempo que há certa desenvoltura com a presença e utilização dos equipamentos audiovisuais, no cotidiano, também há uma reflexão acerca da potencialidade e do alcance da imagem. Isto muito provavelmente advindo de experiências com as equipes de filmagens de canais televisivos que, para realização de documentários ou reportagens, por vezes, procuram moradores cujos comportamentos ou práticas representem a oposição ao ideal de urbanidade; ou num outro extremo, procuram pessoas que sinalizem para alguma espécie de empreendorismo 
e que se sobressaem no aparente "nada". Nestas investidas, algumas equipes de TV pagam às pessoas uma determinada quantia por uma entrevista e imagem. Não por acaso, tempos depois de ter conseguido fazer algumas filmagens da pasteleira da Aldeia (44 anos, casada), esta foi procurada para contar sua trajetória de empreendorismo na doceria alentejana, e revelou-me, tempos depois, com certo orgulho, que não sentiu constrangimento algum em dar a entrevista à televisão.

Por outro lado, talvez o repertório de desconfiança também encontre base na própria inovação tecnológica confrontada com uma espécie de uma "ética aldeã” que vê a utilização de tais recursos, fora do ritual, enquanto uma "negação da tradição". Porém isto dependerá da situação em que tal captação de imagem esteja ocorrendo. Um exemplo, quando estive filmando os homens, na Taberna, ${ }^{14}$ durante o dia, no horário em que costumam reunir-se para tomar uns copos e comer uns "petiscos", um dos homens, guarda da Guarda Nacional Republicana (GNR), fora do seu expediente, começou a fazer indagações enquanto filmava: "Que trabalho estais a fazer?”, "para quem?", “... não trabalhas com uma equipe..." (muito provavelmente, devido ao conhecimento que têm das atividades de arqueólogos que realizaram pesquisas na localidade e as fizeram em equipe). Ou, então, havia também a associação imediata de que tais imagens poderiam ser veiculadas por intermédio da televisão. Novamente repondo a ideia de que poderia mercantilizar as imagens sem que eles tivessem algum conhecimento ou benefício disto.

Não obstante, foi através da linguagem (escrita/virtual) que muitos dos jovens passaram a ser mais espontâneos ao falar de si. O terreno virtual passou a ser outro desdobramento do "campo 
etnográfico", pois, por meio das mensagens instantâneas de MSN, "sms" (telemóveis), aparições no Hi-5, com mensagens e através de fotografias (Fotolog), Facebook, jovens e adultos passaram a manter contato com a pesquisadora; atualizando a respeito dos acontecimentos na Aldeia, realimentando as lembranças. Mas tudo isto é também a tradução de que houve uma escolha deste alguém que passou a ter acesso à rede (virtual) de amig@s. E, se um(a) pesquisador(a) em terreno passa a fazer parte de uma rede social de seus sujeitos, em última instância, é exatamente isto, "são eles quem nos escolhem" (VERGER apud ANDRADE, 2002).

No cotidiano da Aldeia ${ }^{15}$, mesmo em tom de segredo, fala-se sobre o sexo, sobre os afetos. Contrastivamente, pode-se saber da intimidade de outrem por intermédio do pertencimento a uma rede de amizade em que se podem compartilhar segredos, tristezas de amores, mágoas e ofensas, publicados na web na forma de "diários íntimos" (SIBILA, 2008, p. 12). Por vezes, são mensagens de conteúdo amoroso, em tom poético que poderão ser mais estreitamente compreendidas por aqueles e aquelas que estejam sabendo de um episódio íntimo de alguém da rede; por vezes, há a publicização de um pequeno vídeo com close-up do(a) próprio(a) realizador(a), a revelar-se em desabafo e ou em resposta a uma ofensa/mágoa. Por exemplo, o vídeo de um rapaz (18 anos, estudante), tempos depois de ter sido "forçado" a deixar a Aldeia devido a revelação de sua homossexualidade junto à rede de amizades. Entretanto, quando foi possível gravar uma conversa com o referido rapaz, e tendo conseguido fazer imagens em close-up, este não quis falar sobre a sua experiência coming-out, muito menos que isto aparecesse no vídeo que iria produzir. 


\section{$O$ visual e o escrito na memória}

Os moradores, para falarem sobre sexo, fantasias eróticas, constrangimentos vividos na prática sexual, observam quem está à frente; querem ter uma visão do corpo, sobre o outro (o visitante, o outsider), sobre as coisas do mundo, por isso o rosto, os olhos são o principal foco para a avaliação da pessoa que chega. Simultaneamente, somos sujeitos e objetos. Assim, não houve a verbalização fácil e direta sobre os temas do amor, dos sentimentos, apesar dos rumores, dos comentários sobre as pessoas, sobre namoros, casos extraconjugais, na Aldeia alentejana. Tudo isso aconteceu de modo indireto e paulatinamente, em um tempo indeterminado à revelação. $\mathrm{O}$ que houve foram momentos privilegiados que influenciaram o relato; posto que nossos caminhos se cruzaram e nestes cruzamentos, mesmo que planejado anteriormente por uma das partes, neste caso, pela pesquisadora, $\mathrm{o}$ encontro fora sempre imprevisível.

Dito isto, talvez faça sentido mencionar o trecho desta conversa com uma moça (20 anos, estudante, membro da Associação Juvenil): “[...] deixamos entrar as pessoas, mas não toda a gente... apenas aqueles que vemos ser boa pessoa... Tu és boa pessoa.... Comentário que pode ser indicativo de que os jovens da Aldeia não são tão receptivos ou acolhedores como poderia a priori achar, embora fosse recorrente ouvir que na Aldeia as pessoas são todas amigas. Mas o que consideram como sendo uma boa pessoa? Quais os aspectos definidores? Tais questões ainda são um mar de subjetividades, mas que no próprio encontro pesquisadora - sujeitos pesquisados há indícios para a composição do jogo. Em outras ocasiões quando já me tinha feito conhecer junto aos de- 
mais moradores, diziam-me que minha aceitação entre eles devia-se ao meu "feitio"16, neste caso, imagino que para tal colocação devesse acrescentar o adjetivo "bom" (SILVA, 2011).

Por isto, também não pude desconsiderar o fato de que ter explicitado qual o meu interesse junto aos moradores da Aldeia, qual seja a realização da pesquisa sobre a vida afetiva e sexual destes, e que suas narrativas foram feitas à pesquisadora brasileira, para pensar sobre a composição do jogo das imagens. Ou seja, tive que observar que aspectos físicos expressos por meio do modo de vestir, de olhar, de demonstrar empatia, mas ter demonstrado alguma reserva principalmente na presença masculina, para as mulheres, novas, adultas e idosas, talvez tenha contribuído para desconstruir uma determinada imagem de um tipo de mulher brasileira (sensual, provocante, simpática) capaz de alimentar as fantasias masculinas. Imagem esta que, até os dias atuais, não estou certa de que tenha conseguido desmontar totalmente. Talvez tenha lançado elementos que criaram outras imagens, uma espécie de contraimagem da imagem estereotipada. Aquela que viram, e ainda veem, alimentadas nas telenovelas brasileiras, difundidas pelos canais da televisão, mas que ainda recupera ingredientes da imagem da protagonista da telenovela brasileira "Gabriela, Cravo e Canela”, exibida nos idos de 1977 pela televisão portuguesa. ${ }^{17}$

Os comentários e as observações (tanto acerca dos próprios moradores quanto dos moradores sobre a pesquisadora ou "estrangeiro") podem estar muito marcados pelas emoções (conscientes ou não) e, assim, influenciar, também nos valores. Daí que o rosto assume acentuada importância tanto na identificação quanto no investimento. É através do rosto que socialmente se identifica e mais se investe. Isto pressupõe que as pessoas aderem (ou partem) mais 
facilmente aos estereótipos para a identificação. Afirmação pouco eficaz diante de realidades tão flutuantes, principalmente sobre o que diz sobre si ou como se veem uns aos outros cotidianamente (SILVA, 2007). Ainda mais quando não é menor a flutuação e o grau de julgamento que é atribuído a figura do(a) "estrangeiro(a)" ou do(a) "estranho(a)" (daquele/a que é do lugar e é passível de estranhamento no interior do grupo ou por alguém). Neste encontro inacabado, deformado de estranhamento do outro que é semelhante e ao mesmo tempo deslocado, é que o filme, o vídeo inscreve-se enquanto "linguagem de descoberta". Pois nisto implica a nossa abordagem e o objeto alvo de nosso olhar; “[...] não apenas o que olhamos, mas a maneira de olhar, reconhecer, distinguir neste trajeto do olhar e da escuta." (PIAULT, 1995, p. 27-28).

Partindo do pressuposto de que o olho é o nosso sensor e emissor privilegiado dos desejos e conflitos, a imagem, talvez, seja o ponto de maior vulnerabilidade, uma vez que poderá despertar as mais variadas interpretações. Trata-se de uma preocupação sobre si, sobre o que se está emitindo e o que o outro estará pensando a seu respeito, a partir da sua percepção. Mesmo que em alguns momentos, tudo não passe de uma encenação, uma dissimulação, a consciência de si surge enquanto experiência e pode, também, ser a de um corpo constrangido; ou reagente/agressivo; controlado. Como diz Susan Sontag (1981, p. 16-17), “[...] as imagens que mobilizam a consciência estão sempre ligadas a determinadas situações históricas."

Desta maneira, não será menor o grau de confronto de conhecimentos e experiências que os sujeitos poderão ter a partir da visualização de uma fotografia. Como observou Pierre Boudieu (para o caso francês), no tempo em que as fotografias tinham o 
papel de "possibilitar uma representação suficientemente crível e precisa para permitir o reconhecimento", a intenção era que o leitor da fotografia visse os papéis sociais e não somente o indivíduo na sua singular particularidade. A fotografia exercia uma forte influência socializadora, uma vez que por meio desta a mãe ensinava, especialmente "à criança as relações que a unem a cada uma das pessoas na imagem" (BOUDIEU, 2006, p. 34-35). Somente era possível e socialmente aceita para a captação de comportamentos socialmente regulados e solenizados, como as cerimônias de casamento.

Pierre Bourdieu chama atenção para a função que a fotografia teve nas sociabilidades camponesas e tradicionais, para ele, a fotografia cristalizada no formato de "retrato" traduz enquanto postura fotográfica, algum sentimento de honra. $\mathrm{O}$ registro de acontecimentos familiares e da vida coletiva, como os casamentos "preenchia a função de afirmar a unidade, posição e fronteiras das linhagens envolvidas". Tais cerimônias cumpriam momentos de solenidade e ritualidade e, portanto, podiam ser fotografadas (BOURDIEU; 2006, p. 31).

Inspirada pelo estudo de Bourdieu, e por contraste as cerimônias de casamento ou de formaturas na Aldeia alentejana, as fotografias são, quase sempre, tiradas nos momentos em que estão felizes, mas marcam rituais; nos bailes, na Festa da Santa Padroeira (em abril), as imagens da Comissão de Festas (em pose em frente da Igreja Matriz, todos juntos, de pé, em corpo inteiro, alguns com olhar direto para a câmera fotográfica). Notam-se alguns aspectos posturais interessantes acerca da imagem que querem que se tenha deles, entre a fotografia de casamento e os de momentos de celebrações festivas, como a Festa da Padroeira (ritual social), por 
exemplo, que integra e atrai as várias aldeias do baixo Alentejo, bem como, da localidade da fronteira espanhola. Ou seja, nestas fotografias querem ou dão-se a ser fotografados, quase sempre, em movimentação, concentrados na ação e indiferentes à câmera (ou a quem os fotografa). Entretanto, foi durante uma gravação, no interior da casa de uma entrevistada (50 anos, casada, empregada), diante da fotografia de seu casamento exposta num móvel encostado à parede logo após a porta de entrada, que sua fala revelou-me outro sentimento. Diz: “eu não estava feliz naquele dia..." 18

Bourdieu (2006), com base numa nota de Loïc Wacquant e Richard Nice, diz que "[...] a fotografia é a situação na qual a consciência do próprio corpo perante os outros atinge a máxima acuidade. Cada um sente-se sob o olhar e sob um olhar que fixa e imobiliza as aparências." (BOUDIEU, 2006, nota 18 da p. 38). Todavia, se os moradores "dão" a imagem que "querem dar" ou simplesmente "dão a sua imagem", é importante observar que se nos momentos de festa estão menos preocupados em passar uma imagem rígida de si, menos controlada (uma vez que há uma mescla de distintas pessoas e camadas sociais), é nas gerações dos avós ou dos pais que se observam algumas "convencionalidades na postura e na roupa adotada para a fotografia" (BOUDIEU, 2006, p. 38). Como num episódio ${ }^{19}$ em que estava com a câmera de vídeo ligada e ao presenciar uma demonstração de afeto entre avô e neta, num ambiente da casa, de rotina de domingo, chamei-os a atenção para a filmagem. $\mathrm{O}$ avô (78 anos) fixou o olhar na câmera e assumiu imediatamente uma postura firme endireitando o tórax, mesmo tendo a neta com os braços enlaçados ao seu pescoço. Postura esta que foi percebida pela mesma e a fez exclamar: "Ele 
pensa que está tirando fotografia! Ela está filmando (avô)!” Ele indiferente ao comentário da neta, apenas desfez a postura dizendo: “Já está!”. Era um sinal para que eu parasse de filmar, mas também da ideia que aquele senhor tinha de que o tempo para o "clicar" da máquina fotográfica já tinha se dado.

Se no caso francês, estudado por Pierre Bourdieu, as fotografias de casamento eram a representação do que pode ser fotografado, para o caso da Aldeia alentejana, quando se observa fotos de jovens, junto com os pais (em cerimônias religiosas, escolares, aniversários, batizados), nota-se que há também alguma preocupação em passar uma imagem "controlada". Todavia, quando as fotos são tiradas e demonstradas pelos mesmos (ou quando se dão a fotografar por outrem), as fotografias querem justamente dar a entender e enfatizar o contrário: alegria, a satisfação do convívio sem muita preocupação em apresentar a "melhor imagem de si", posto que o "melhor de si" já está sendo captado, no festejo, na sociabilidade entre os pares, entre os amigos; no caráter amistoso das relações sociais. Nestes termos, e como também observou Bourdieu, “[...] o verdadeiro objecto da fotografia não são os indivíduos, mas as relações entre eles." (BOUDIEU, 2006, p. 34). Então, se nas solenidades a fotografia é o registro que congela o tempo e assegura a visão do que deve ser perpetuado, a rotina pode dizer o contrário. $\mathrm{Na}$ vida cotidiana captar uma imagem, fora do ritual, pode ser uma espécie de invasão da vida privada (e íntima). Observou Bourdieu que, no espaço da casa, nem todo e qualquer tipo de foto pode estar à disposição para quem quiser ver; estas são guardadas para os espaços dos quartos.

$\mathrm{Na}$ Aldeia alentejana, no espaço dos quartos, sobretudo dos jovens, pode-se visualizar fotografias de momentos de maior expo- 
sição, poses e demonstrações dos corpos, de rapazes e raparigas. Ou, então, as fotografias dos ídolos, como atores dos "Morangos com Açúcar" ${ }^{20}$, cantores e cantoras do pop rock americano, nacional ou espanhol. Porém, mesmo no dia a dia, fora de eventos festivos, nem todos os jovens e demais moradores ficam à disposição para que ocorra uma filmagem, principalmente se estiverem em espaços públicos da Aldeia. Todavia, no âmbito da casa, momentos ímpares e de relativa familiaridade com a presença da câmera, puderam ser captados, e nestes momentos foi possível focar as imagens em close-up, gravar as conversas mais descontraídas. Salientando que, nesta Aldeia alentejana, entrar na casa de qualquer morador já é um acontecimento a ser conquistado.

Por isto, e porque observo que no caso da Aldeia a preocupação com a imagem é algo importante para os moradores, me interessei em confrontar-me com esta experiência contínua de aprendizagem do uso e das técnicas da imagem na pesquisa, para pensar no que ela pode desencadear quando anuncia algo e ao mesmo tempo, esteticamente, pode não corresponder a este algo. Ou seja, se digo que tal vídeo etnográfico exploratório nasce de uma pesquisa acerca das "experiências e representações da sexualidade entre jovens portugueses em meio rural", penso que é quase que automático que haja uma associação e uma expectativa de ver imagens de jovens trocando carícias, beijos, exposição de corpos femininos e masculinos, enfim, imagens que apelem para a excitação e o erotismo.

Assim, não é inevitável descolar as associações que muitos fazem acerca do universo rural e das pessoas que nele vive, de pouco modernas, com pouco requinte ou pouco ligadas as tecnologias etc., quase sempre em oposição aos valores citadinos. Tanto num caso como no outro, as representações que temos e/ou produzi- 
mos acerca de um tema ou dada realidade abrem um leque para indagações, desconstruções e outras construções enquanto que aumenta a consciência de nossas limitações técnicas, da nossa forma de coletar ou documentar; a limitação de nosso olhar. Ou seja, no desafio de captação das imagens somos precipitados ao que nos escapa, ao que não conseguimos dizer através de uma foto ou filmagem e nisto damos conta de que não temos um "documento social em termos absoluto", como observou José de Souza Martins (2008); bem como a palavra falada, o depoimento, a entrevista não é em termos absolutos, a referência antropológica, sociológica (MARTINS, 2008, p. 11), devido as dificuldades de sua insuficiência e suas limitações. Ou seja, estamos num campo aberto.

Desta maneira, andamos no campo dos sujeitos sociais tateando a procura de conhecer o que olhar e registrar com as imagens, enquanto vamos "violentando e invadindo o corpo coletivo invisível" capturando as imagens que talvez julguemos corresponder ou representar aquilo que queremos dizer ou mostrar consoante o tema de nossa pesquisa. E me pergunto: rompemos ou apenas reproduzimos estereótipos? Dominamos o código de visualidade daqueles que pesquisamos?

Escreve José de Souza Martins (2008, p. 16) que o(a) pesquisador(a):

Pode obter a informação visual que procura, em função dos pressupostos teóricos de sua pesquisa, mas obterá um dado mutilado e desprovido da informação cultural que o situa e explica se não observar as regras de acesso a situações e espaços sociais. Sobretudo se desconhecer a cultura visual e do olhar das populações que visita e estuda. Convém ter presente, sempre, que na sociedade tudo é regulamentado, mesmo aquilo que não parece sê-lo. 
Deste modo, e tomando a "fotografia enquanto um documento da sociabilidade, expressão de mentalidades e de perspectivas que se refletem na composição fotográfica e que expressam as experiências diferenciais em uma dada estrutura de classes", como diz Martins (2008), é que (talvez) conseguimos nos depurar do invasivo e nos aproximar do conhecimento que o fotografado ou filmado tem sobre o visual. Por isto, e para tentar me aproximar de tal conhecimento, foi que me aventurei em demonstrar o que fotografei e o filmei, tanto na pesquisa realizada no Brasil quanto na Aldeia do Baixo Alentejo.

Assim, tendo a possibilidade de quase que instantaneamente demonstrar a imagem ao sujeito filmado, isto teve o efeito de "apaziguador" (mesmo que momentâneo) das dúvidas sobre "o que" e "o como" editar determinadas imagens e depoimentos. O feedback da pessoa (logo após o que viu) foi sinalizador para a pré-edição das imagens, consequentemente para o processo final de edição do vídeo. Vídeo este que será devolvido à Aldeia. Esta informação fez com que os sujeitos se manifestassem com mais ênfase, porque houve conteúdos que, em alguns casos, não deveriam ser vistos pelos demais moradores; ou, em particular, por um determinado membro da família. Mas que pôde ser captado pela pesquisadora, justamente, por ter estado num daqueles momentos favoráveis em que as pessoas estão disponíveis para falar, para mostrarem-se. A demonstração do vídeo experimental ("Para Ti Amor”, duração: 12 min.) aumentou o entendimento - da pesquisadora acerca de seus sujeitos e talvez dos mesmos acerca da pesquisadora -, ou seja, na medida em que a amizade e a confiança aumentaram, foi possível repetir as conversas e os detalhes e revelações que no início foram encobertos e dissimulados, foram sendo esclarecidos, confirmados. 
O vídeo, deste modo, inscreve-se na memória pelas imagens, “[...] imagens mentais que são responsáveis pela flutuação da memória do presente e do futuro para o passado." (LEITE, 2000). É texto visual de uma escrita da conclusão pelos fragmentos e recortes. É também o desafio da experiência da criação, da imagem como arte de filmar, de fotografar, arte para lidarmos com nosso corpo, nossas emoções, nossa memória. Por meio da criação de uma narrativa que não seja linear, que não preencha os silêncios, o vídeo, o filme pode possibilitar a recriação de sentidos pelo expectador. É neste interstício que retira o sujeito da sua condição de passividade, fazendo com que participe na recriação da imagem que podemos vislumbrar o papel importante que as técnicas fílmicas têm na captação dos sentidos das imagens; desconstruindo as cenas naturalizadas, guiando nosso olhar para o que tensiona o nosso entendimento das coisas do mundo, e não apenas confirma o que existe ou julgamos saber. Assim sendo, considerar as muitas imagens que perpassam nosso cotidiano pode ser um exercício de aprendizagem, uma forma de enriquecimento da nossa imaginação; uma maneira de abrir outras lentes criando novos olhares sobre aquilo que queremos, que sociedade, que escola, que tipo de saúde, de governo, de Estado.

\section{Referências}

ANDRADE, R. Fotografia e Antropologia: olhares fora-dentro. São Paulo: Estação Liberdade; EDUC, 2002.

ALMEIDA, M. J. de. Imagens e Sons: a nova cultura oral. São Paulo: Cortez, 2001. 
BOURDIEU, P. O camponês e a fotografia. Revista de Sociologia e Política, Curitiba, n. 26, p. 31-39, jun. 2006.

CABRAL, J. de P. 'Aromas de urze e de lama': reflexões sobre o gesto etnográfico. Etnográfica, p. 191-212, maio 2007.

CAMPOS, R. Movimentos da imagem no graffiti: das ruas da cidade para os circuitos digitais. In: CARMO, R. M.; SIMÕES, J. A. (Orgs.). A Produção das Mobilidades (Redes, Espacialidades e Trajectos). Lisboa: Imprensa de Ciências Sociais, 2009. p. 91-112.

CARACTERIZAÇÃO GENÉRICA DO CONCELHO DE SERPA, C.M.S., 2001.

CARMO, R. M. De aldeia a subúrbio: trinta anos de uma comunidade alentejana. Lisboa: Imprensa de Ciências Sociais, 2007.

CARRILHO, M. J. População Activa: Conceito e Extensão através dos Censos. Lisboa: Instituto Nacional de Estatística, 1996.

CERTEAU, M. de. A Invenção do Cotidiano: 1. Artes de fazer. 9. ed. Petrópolis: Vozes, 1994.

CUNHA, I. F. A revolução da Gabriela: o ano de 1977 em Portugal. Cadernos Pagu, n. 21, p. 39-73, 2003.

ELIAS, N.; SCOTSON, J. L. Os estabelecidos e os outsiders: sociologia das relações de poder a partir de uma pequena comunidade. Tradução Vera Ribeiro. Rio de Janeiro: Jorge Zahar, 2000.

FONSECA, C. A noética do vídeo etnográfico. Horizontes Antropológicos - Antropologia Visual (revista temática semestral), Porto Alegre, ano 1, n. 2, p. 143-56, 1995.

FOUCAULT, M. História da Sexualidade I: a vontade de saber. Rio de Janeiro: Edições Graal, 1988.

O que é um autor? Portugal: Veja/Passagens, 2002. 
FRANÇA, J. M. C. O historiador globalizado. Folha de São Paulo, São Paulo, 1. set. 2002. Caderno Mais!, p. 6.

GEERTZ, C. A Interpretação das Culturas. Rio de Janeiro: LTC, 1989.

GIDDENS, A. A Transformação da Intimidade: sexualidade, amor e erotismo nas sociedades modernas. São Paulo: Editora da Universidade Estadual Paulista, 1993.

GODOLPHIM, N. A fotografia como recurso narrativo: problemas sobre a apropriação da imagem enquanto mensagem antropológica. Horizontes Antropológicos - Antropologia Visual (revista temática semestral), Porto Alegre, ano 1, n. 2, p. 125-142, 1999.

HARAWAY, D. Saberes localizados: a questão da ciência para o feminismo e o privilégio da perspectiva parcial. Cadernos Pagu, n. 5, p. 7-42, 1995.

KOSSOY, B. Realidades e ficções na trama fotográfica. Cotia: Ateliê Editorial, 2000.

LEITE, M. L. M. Imagens da memória (entre o legível e o visível). Revista de Antropologia, São Paulo, v. 43, n. 2, 2000.

MARTINS, J. S. de. Introdução. In: (Org.). Vergonha e Decoro na Vida Cotidiana da Metrópole. São Paulo: Hucitec, 1999.

Sociologia da fotografia e da imagem. São Paulo: Contexto, 2008.

NIEMEYER FILHO, A. Ver e Ouvir (A maneira mais fácil de escrever, filmar, editar, reproduzir e trabalhar em vídeo). Brasília: Editora UnB, [s.d.].

PAIS, J. M. Jovens e cidadania. Sociologia, Problemas e Práticas, n. 49, p. 53-70, 2005.

PARKER, Richard G. Corpos, prazeres e paixões: a cultura sexual no Brasil contemporâneo. São Paulo: Best Seller, 1991. 
PIAULT, M-H. A antropologia e a 'passagem à imagem'. Cadernos de Antropologia e Imagem, n. 1, p. 23-29, 1995.

PINK, S. Doing: Visual Ethnography - Images, Media and Representation in Research. London: SAGE Publications, 2001.

RIBEIRO, A. O corpo que somos: aparência, sensualidade, comunicação. Lisboa: Editorial Notícias, 2003.

SANTOS, C. S. dos; AGUIEIROS, G. H. O corpo e a intimidade: os espaços do constrangimento. In: MARTINS, J. de S. (Org.). Vergonha e decoro na vida cotidiana da metrópole. São Paulo: Hucitec, 1999. p. 105-122.

SANTOS, M. O Lugar e o Cotidiano. In: . A Natureza do Espaço: Técnica e Tempo, Razão e Emoção. São Paulo: Editora da Universidade de São Paulo, 2002. p. 313-330.

SCOTT, J. W. Experiência. In: SILVA, A. L. da; LAGO, M. C. de S.; RAMOS, T. R. O. (Orgs.). Falas de Gênero: teorias, análises, leituras. Florianópolis: Editoras Mulheres, 1999. p. 21-55.

SIBILIA, P. O show do eu: a intimidade como espetáculo. Rio de Janeiro: Nova Fronteira, 2008.

SILVA, V. A. da. As flores do pequi. Sexualidade e vida familiar entre jovens rurais. Campinas: CMU-Publicações e Editora Arte Escrita; São Paulo: FAPESP, 2007.

. Interdições e Prazeres: estigma, vergonha e constrangimentos. In: PAIS, J. M.; BENDICT, R.; FERREIRA, V. S. (Orgs.). Jovens e Rumos. Lisboa: Imprensa de Ciências Sociais, 2011. p. 295-314.

SONTAG, S. Ensaios sobre fotografia. Rio de Janeiro: Arbor, 1981.

SOBRAL, J. M. Memória e Identidade Nacional: considerações de caráter geral e o caso português. In: SILVA, M. C. (Org.). Nação e Estado, Entre e Global e o Local. Porto: Edições Afrontamento, 2006.

TORRES, A. Amor e Ciências Sociais. Travessias, 2004. 
WOLF, M. Sociologia de la vida cotidiana. 4. ed. Madri: Cátedra, 2000.

ZUMTHOR, P. Performance, recepção, leitura. São Paulo: Editora da PUC, 2000.

\section{Notas}

* As ideias e reflexões neste trabalho são fruto de revisões e ampliações de apresentações em eventos acadêmicos, como o Seminário "Interdisciplinaridade em Acção", no IHC, em junho de 2010, em Lisboa; a comunicação apresentada na 27ª Reunião Brasileira de Antropologia, realizada entre os dias $1^{\circ}$ e 4 de agosto de 2010, em Belém, Pará, Brasil. Disponível no link: <http://www.iconecv.com. $\mathrm{br} / 27 \mathrm{rba}$ /arquivos/grupos_trabalho/gt08/vas.pdf $>$, com outro título; também de um subcapítulo da tese de doutoramento, publicada com o título "As flores do pequi: sexualidade e vida familiar entre jovens rurais" (2007).

** Doutora em Ciências Sociais. Investigadora colaboradora em projetos financiados pela Fundação para a Ciência e a Tecnologia (FCT), no CRIA-IUL (Centro em Rede de Investigação em Antropologia, no Instituto Universitário de Lisboa) e no ICS-UL (Instituto de Ciências Sociais da Universidade de Lisboa). E-mails:<vandas7@yahoo.com.br $>$; <vandaaparecida.silva@gmail.com $>$.

${ }^{1}$ Localizada na zona de fronteira de Portugal (Alentejo) e Espanha (Andaluzia), a Aldeia conta com cerca de 1,5 mil habitantes. Fonte: Caracterização Genérica do Concelho de Serpa, C.M.S., 2001. Neste texto opta-se pela não identificação do nome da Aldeia.

${ }^{2}$ Período em que Portugal passa do regime ditatorial de Oliveira Salazar para o regime democrático.

${ }^{3}$ Também optei pela mesma conduta nas pesquisas de terreno que realizei no Brasil, na região do Vale do Jequitinhonha (MG), nos períodos do mestrado, de 1997 a 1999, e do doutoramento, de 2001 a 2004.

${ }^{4} \mathrm{E}$ na medida em que alguma confiança entre os sujeitos e a pesquisadora foi se consolidando, uma entrevista mais aprofundada pode ser feita; também utilizei a técnica das entrevistas a jovens em idades subsequentes para a "reconstrução retrospectiva das biografias" (HEILBORN et al., 2002, p. 15). Sobretudo quando foi preciso contornar alguns obstáculos, como a timidez de jovens da faixa etária pretendida (grupo focal $14-25$ anos de idade), bem como a dificuldade em falar sobre a intimidade, por exemplo.

${ }^{5}$ De Pós-doutoramento intitulada "Experiências e representações de sexualidade entre jovens portugueses em meio rural”, financiada pela Fundação para a Ciência e a Tecnologia (FCT), SFRH/BPD/25776/2005. A pesquisa de terreno foi realizada no período de 2006 a 2010.

${ }^{6}$ Juntamente com o "Facebook", esta é uma das redes sociais mais importantes em Portugal. Cf. Gustavo Cardoso (do Centro de Investigação e Estudos 
de Sociologia - CIES, e ISCTE-IUL), durante o Fórum para a Sociedade da Informação - Governação da Internet, realizado no ISCTE-IUL, em 8 de julho de 2010.

${ }^{7}$ Que foram tiradas durante as viagens de visita ao terreno e reproduzidas em formato de vídeo (duração: 12 minutos). Os vários momentos do cotidiano dos sujeitos entrevistados, assim como, demais moradores, nos festejos religiosos, casamento e bailes escolares foram objecto para o clique das máquinas fotográficas (Pentax K-1000, manual, objetiva $50 \mathrm{~mm}$ e uma automática). Tal material faz parte da dissertação de mestrado intitulada "Eles não têm nada na cabeça: jovens do sertão mineiro entre a tradição e a mudança". Faculdade de Educação. Unicamp, 2000.

${ }^{8}$ Uma filmadora do tipo camcorder (modelo DCR-HC38E): “[...] são filmadoras que funcionam também como vídeo, possibilitando ligá-las à televisão e assistir a qualquer filme ou ao que foi filmado por meio delas. Nas camcordes, a fita é colocada na própria filmadora." (NIEMEYER FILHO, [s.d.]).

${ }^{9}$ Agradecimentos sinceros a Maria João Taborda (doutoranda no ISCTE-IUL) com quem venho dialogando sobre os usos da imagem na pesquisa, assim como, acerca da técnica. Maria João tratou da edição das imagens e trabalhamos juntas nisto. Nada foi feito sem que a pesquisadora não estivesse ao lado do computador (a ilha de edição).

${ }^{10}$ Muito embora, talvez, o rapaz não tivesse a percepção ou intenção de nomearse como um "writer" ou membro de alguma comunidade que faz graffiti.

${ }^{11}$ Esta referência, bem como a utilização da imagem, do recurso do vídeo para abrir outras possibilidades narrativas e cognitivas, é inspirada em Carlos Ginzburg e sua observação acerca da micro-história e seu gosto pelo ensaio (FRANÇA, 2002, p. 6).

${ }^{12} \mathrm{Tal}$ Associação conta um número que oscila entre 100 e 110 associados. Foi fundada em julho de 2001.

${ }^{13}$ Nome que obedece a um regionalismo e que quer dizer "caracol grande" (Cf. DICIONÁRIO LÍNGUA PORTUGUESA. Porto: Porto Editora, [s.d.]. p. 151). Muito apreciada, as caracoletas (e os caracóis) são apanhados no campo. Depois de muito bem lavados, vão para uma panela onde são preparados num caldo a base de sal, pimenta (malagueta), cubo de caldo de galinha; como vi preparar numa cozinha de uma casa da Aldeia.

${ }^{14}$ Espaço de sociabilidade masculina, exclusivamente para consumo de bebidas alcoólicas, cigarros e "petiscos".

${ }^{15}$ E não menos no cotidiano de Rosário das Almas, no Vale do Jequitinhonha (MG). Ver Silva (2007).

${ }^{16}$ Cf. Infopédia - Enciclopédia e Dicionários Porto Editora, "feitio: 1. Forma; configuração; 2.talhe; 3 . modo de ser ou carácter de imã pessoa; temperamento; índole; génio; 4 . Trabalho do alfaiate, da costureira ou de outro artífice 5. Preço desse trabalho". Disponível em: <www.infopedia.pt $>$. Acesso em: consultado em: 15 fev. 2013.

${ }^{17}$ Cf. Cunha (2003, p. 44; p. 53): “Em 1977, ainda sem a Lei da Televisão em 
vigor, o avolumar dos problemas orçamentais (provocados em parte pela fuga à taxa obrigatória) das crises laborais partidarizadas, levam a uma reestruturação da televisão e à reformulação de programas. É nesta conjuntura que surgem dois programas, 'A visita da Cornélia' (um concurso reallity show) e a telenovela 'Gabriela, Cravo e Canela', que alterarão o percurso da telenovela em Portugal ao mesmo tempo que anteciparão e simbolizarão a emergência de uma nova sociedade e estilos de vida centrados no consumo e nos media. [...] Sabendo-se que, em 1977, o número de aparelhos de televisão por mil habitantes rondava os 150 e que era prática corrente, nas aldeias, vilas e bairros, assistir-se à telenovela nos cafés, associações de bairro, associações de moradores ou sedes de outras associações cooperativas, pode-se imaginar o 'efeito' de interactividade criado pelo simples facto de fruição conjunta da exibição.”

${ }^{18}$ Importante salientar que esta depoente, ao ver a gravação, pediu-me que não mostrasse a passagem em que dizia que "não estava feliz no dia do seu casamento" porque senão o marido poderia lhe matar (talvez num sentido figurado). Porém, das observações de campo, pode-se saber que na trajetória da vida conjugal, esta depoente foi vítima de violência doméstica, por parte de seu marido.

${ }^{19}$ Diário de campo de 2 maio 2010. Dia das Mães em Portugal.

${ }^{20}$ Trata-se de uma série juvenil portuguesa transmitida pelo canal TVI desde 2003. 
